\title{
Simple, affordable, and sustainable borehole observatories for complex monitoring objectives
}

\author{
A. Kopf, T. Freudenthal, V. Ratmeyer, M. Bergenthal, M. Lange, T. Fleischmann, S. Hammerschmidt, C. Seiter, and \\ G. Wefer \\ MARUM - Center for Marine Environmental Science, University of Bremen, Bremen, Germany \\ Correspondence to: A. Kopf (akopf@marum.de)
}

Received: 24 September 2014 - Published in Geosci. Instrum. Method. Data Syst. Discuss.: 15 December 2014

Revised: 18 March 2015 - Accepted: 7 April 2015 - Published: 18 May 2015

\begin{abstract}
Seafloor drill rigs are remotely operated systems that provide a cost-effective means to recover sedimentary records of the upper sub-seafloor deposits. Recent increases in their payload included downhole logging tools or autoclave coring systems. Here we report on another milestone in using seafloor rigs: the development and installation of shallow borehole observatories.

Three different systems have been developed for the MARUM-MeBo (Meeresboden-Bohrgerät) seafloor drill, which is operated by MARUM, University of Bremen, Germany. A simple design, the MeBoPLUG, separates the inner borehole from the overlying ocean by using o-ring seals at the conical threads of the drill pipe. The systems are selfcontained and include data loggers, batteries, thermistors and a differential pressure sensor. A second design, the so-called MeBoCORK (Circulation Obviation Retrofit Kit), is more sophisticated and also hosts an acoustic modem for data transfer and, if desired, fluid sampling capability using osmotic pumps. In these MeBoCORKs, two systems have to be distinguished: the CORK-A (A stands for autonomous) can be installed by the MeBo alone and monitors pressure and temperature inside and above the borehole (the latter for reference); the CORK-B (B stands for bottom) has a higher payload and can additionally be equipped with geochemical, biological or other physical components. Owing to its larger size, it is installed by a remotely operated underwater vehicle (ROV) and utilises a hot-stab connection in the upper portion of the drill string. Either design relies on a hot-stab connection from beneath in which coiled tubing with a conical drop weight is lowered to couple to the formation. These tubes are fluid-saturated and either serve to transmit pore pressure signals or collect porewater in the osmo-sampler. The third de-
\end{abstract}

sign, the MeBoPUPPI (Pop-Up Pore Pressure Instrument), is similar to the MeBoCORK-A and monitors pore pressure and temperature in a self-contained manner. Instead of transferring data on command using an acoustic modem, the MeBoPUPPI contains a pop-up telemetry with iridium link. After a predefined period, the data unit with satellite link is released, ascends to the sea surface, and remains there for up to 2 weeks while sending the long-term data sets to shore.

In summer 2012, two MeBoPLUGs, one MeBoCORK$A$ and one MeBoCORK-B were installed with MeBo on RV Sonne, Germany, in the Nankai Trough area, Japan. We have successfully downloaded data from the CORKs, attesting that coupling to the formation worked, and pressure records were elevated relative to the seafloor reference. In the near future, we will further deploy the first two MeBoPUPPIs. Recovery of all monitoring systems by a ROV is planned for 2016 .

\section{Introduction}

Around 20 years ago, the scientific community started to use borehole observatories, so-called CORKs, which were installed inside submarine boreholes, and which allowed the re-establishment and monitoring of in situ conditions (see summary in Davis and Becker, 2001). The key principle as well as the main objective is to provide a hydraulic seal between the borehole environment and the overlying body of water body (ocean) (Fig. 1). Based on this principle, various types of instruments with different capabilities have been developed over the past decades, the majority of those with scientific purposes within the Ocean Drilling Program (ODP) 
and the Integrated Ocean Drilling Program (IODP; see review by Becker and Davis, 2005).

From the first CORKs, which allowed only rudimentary fluid pressure and temperature measurements, the instruments evolved to multi-functional and multi-level subseafloor laboratories including, for example, hydrologically isolated zones with casing screens (e.g. Davis et al., 2006), thermistor strings (e.g. Davis and Villinger, 2006), long-term fluid sampling devices (Solomon et al., 2009), in situ microbiological experiments (Orcutt et al., 2010), or strainmeter (Kopf et al., 2011a). The advantages of long-term monitoring are the ability to obtain (1) a reliable measurement of ambient pore pressure (this measurement often requires significant time after drilling to re-equilibrate to original in situ conditions and usually cannot be obtained by downhole tools); (2) formation elastic and hydrologic properties determined from the response to tidal and seismic loading (e.g. Wang and Davis, 1996; Davis et al., 2006); (3) records of hydraulic transients associated with, e.g. seismic and aseismic slip, fluid flow events, and possible precursory phenomena, over a wide range of timescales and rates (e.g. Davis and Becker, 2001; Davis et al., 2006); (4) temperature anomalies associated with fluid flow episodes (Davis and Villinger, 2006) or as precursors to earthquakes (Johnson et al., 2000); and (5) transient changes in the chemical composition or the seepage rate (Brown et al., 2005). The phenomena have in common that they are episodic in nature, and time series data are the only feasible way of increasing our understanding of them.

Nonetheless, most boreholes are still left uninstrumented, which is a major loss for the scientific community. Installation of CORKs usually requires a drillship, which is a major logistic and financial effort. Moreover, the increasing complexity of the CORK systems not only increased the expenses but also led to longer installation times and a higher sensitivity of the instruments to environmental constraints.

An affordable alternative to the drill ships is currently seen in the seafloor drills, which are tethered, remotely controlled devices that can be run from ships of opportunity provided they offer sufficient space and a strong enough A-frame. One such seafloor drill is the MARUM-MeBo (MeeresbodenBohrgerät, the German term for seafloor drill rig), which has recently been developed at MARUM, University of Bremen (Germany) (see details in Freudenthal and Wefer, 2013). The MeBo70 can be operated from any large research vessel and allows for coring to a depth of $70 \mathrm{~m}$ in either push coring mode for soft sediments or rotary coring mode for hard rock drilling. A second device, MARUM-MeBo200, is currently under implementation and will core to $200 \mathrm{~m}$ below seafloor (b.s.f.) with the majority of the other parameters similar to the first one (see below).

In this paper we describe our main objectives for implementing observatories into MeBo boreholes. Foremost, this is the efficiency of a single round trip of the seafloor drill and observatory unit (whereas drill ships always need a sec-

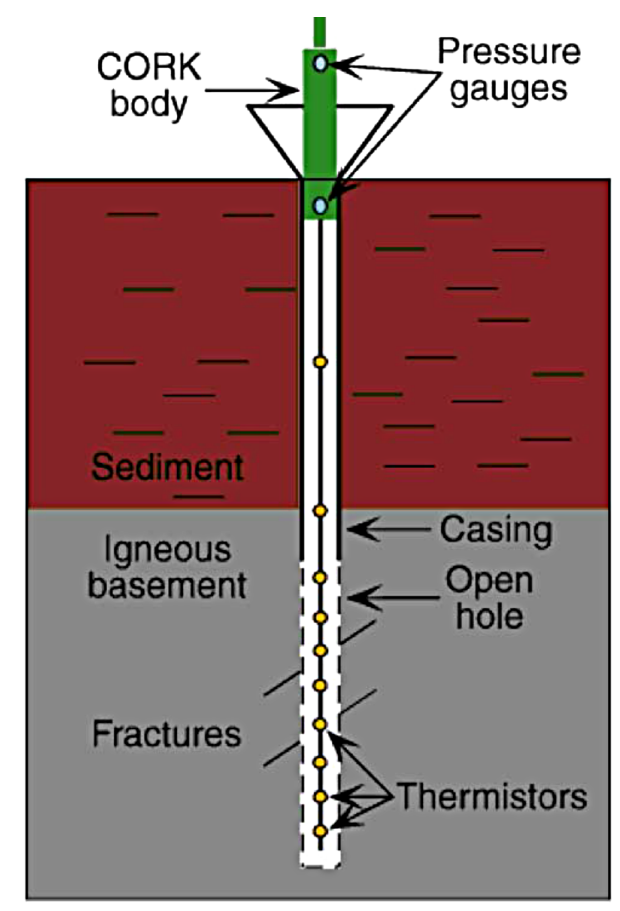

Figure 1. Schematic of a CORK observatory's main components: Here an example in sediment-laden oceanic crust and a simple CORK head with seal and $\mathrm{P}$ transducers (green unit with light-blue sensors) plus a thermistor string (self-contained; see yellow circles). From Becker and Davis (2005).

ond round trip by pipe or wire in order to deploy the borehole instrument). Second, the rather generic and modular design is the second objective whereby a wealth of parameters may be monitored in a variety of settings. In the following, we present three types of miniature borehole observatories, which on the one hand have evolved back to more simple systems when compared to ODP/IODP CORKs, but which on the other hand provide a wide range of possible in situ measurements. In addition to the technological concept, we report on the first installation of such MeBo observatories in the Nankai Trough area off the shore of Japan, therefore providing a proof of concept.

\section{State of the art: seafloor drills}

Seafloor robotic drills bridge the gap between conventional seabed sampling techniques from multi-purpose research vessels (like gravity coring or dredging) and dedicated drilling vessels. Working from a stable platform at the seabed, which is not affected by ship movements due to wave heave or currents, ensures optimised control on the drilling process. As a consequence of the increased demand of core drillings in the range of $10-200 \mathrm{~m}$ for geotechnical site investigation or mineral ore exploration, a variety of seabed drill rigs have been developed within the last decade (McGinnis, 
2009). They are, however, more or less all in the prototype stage, with the MARUM-MeBo being one of the most developed systems (see review in Freudenthal and Wefer, 2013).

\section{The MeBo seafloor drill rig}

MeBo is a robotic drill that is deployed on the seabed and remotely controlled from a sea vessel. The complete MeBo system, including drill, winch, launch and recovery system, control unit, as well as workshop and spare drill tools, is shipped within six $20 \mathrm{ft}$. containers (one of which carries the MeBo drill itself; Fig. 2). A steel armoured umbilical with a diameter of $32 \mathrm{~mm}$ is used to lower the 10-ton heavy device to the seabed where four legs are then extended in order to increase the stability of the rig. Copper wires and fibre optic cables within the umbilical are used for energy supply from the vessel and for communication between the MeBo70 and the control unit on the deck of the vessel. The maximum deployment depth in the current configuration is $2000 \mathrm{~m}$.

The mast with the feeding system forms the central part of the drill rig. The drill head provides the required torque and rotary speed for rock drilling and is mounted on a guide carriage that moves up and down the mast with a maximum push force of 4 tons. A water pump provides sea water for flushing the drill string for cooling of the drill bit and for removing the drill cuttings. Core barrels and rods are stored on two magazines on the drill rig. Wireline core barrels (HQ - hole and core diameter) and hard metal drill bits with a $55 \mathrm{~mm}$ core diameter (push coring) are usually used in soft marine deposits. The stroke length is $2.35 \mathrm{~m}$ each. With complete loading of the magazines, a maximum coring depth of more than $70 \mathrm{~m}$ can be reached. Station time can reach more than $24 \mathrm{~h}$ per deployment. For a more detailed description of the MeBo70 see Freudenthal and Wefer $(2009,2013)$.

In 2014, a refined, taller MeBo drill rig with larger terminal borehole depth $(200 \mathrm{~m}$ b.s.f.) and operational water depth $(3000 \mathrm{~m})$ was developed and successfully tested during trials in the North Sea. Details can be found at http: //www.marum.de/en/MeBo200.html on the MARUM website. A next step will be the implementation of the observatories introduced in this paper once the drilling system is fully operational in deep water.

\section{Methodology}

\subsection{Methodological objectives}

Among the tasks we try to achieve with the MeBo borehole observatories, there are four that are fundamental:

1. seal the borehole;

2. collect data over long periods of time;

3. transfer data to the scientist/end user;

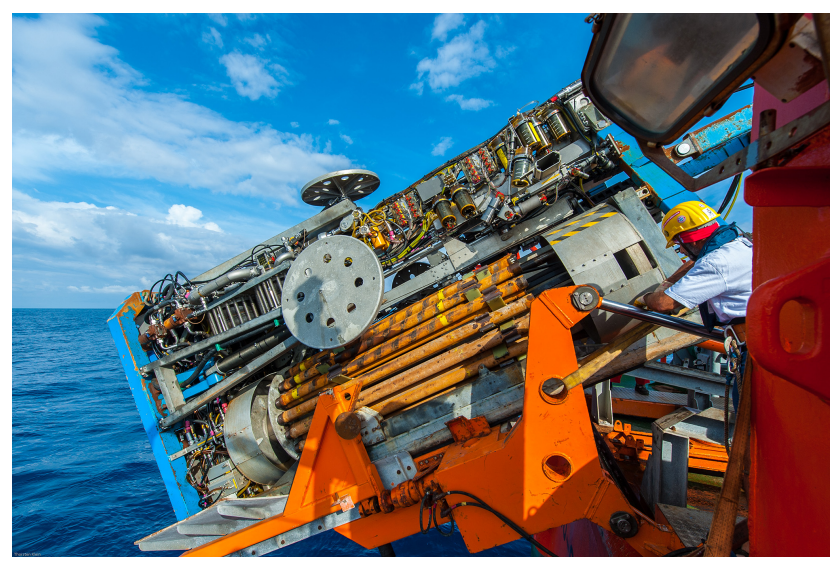

Figure 2. MARUM-MeBo70 drill rig during launch on the aft deck of RV Sonne. For details regarding the individual components of the system as well as specifications, refer to Freudenthal and Wefer (2013).

4. increase capability by adding payload.

Our concept is very generic. Tasks 1 and 2 are mandatory and realised in all three MeBo observatory systems, whereas tasks 3 and 4 provide a suite of options that can be tailored to the needs of an individual campaign.

\section{Borehole seal}

The MeBo seafloor drill uses H-size HQ wireline coring tools. The outer diameter of the drill rods is $98 \mathrm{~mm}$. During routine drilling operations, these pipes are used to extend the drill string downhole, and are recovered once terminal depth of a given hole is reached (Freudenthal and Wefer, 2013). Each HQ rod has a male end with a conical thread at the base and a female conical thread at the top end.

If an observatory is to be set with MeBo, procedures change in the sense that some drill pipes (i.e. several of the $2.35 \mathrm{~m}$ long rods) remain in the ground and serve as casing to stabilise the upper portion of the hole where the soft sediments would otherwise close in. The final, uppermost drill rod is then prepared to provide the borehole seal. In addition, this rod has a widened outer diameter so that it will facilitate a seal at the seafloor where the drilling operation may have excavated the ground. Note that the eventual sealing of the system occurs via sediment infilling around the outside of the drill rods left in place, in addition to the widened upper part and the seals inside the drill rod string. This is different from the traditional CORK seals where concrete, packers, and o-ring seals are utilised (see Becker and Davis, 2005), but cementing is impossible for MeBo and packer systems for MeBo rods are not even in the prototype stage today.

The two main principles to have a sealed upper rod are to screw in an instrumented plug having the shape of the conical thread and additional o-ring seals, or to prepare an entirely new instrumented rod of up to $2.35 \mathrm{~m}$ length with a 
hot-stab seal in the middle. These two principles have been used in designs of the so-called MeBoPLUG and the MeBoCORK (Circulation Obviation Retrofit Kit)-A (A stands for autonomous) and MeBoCORK-B (B stands for bottom) (see Sect. 3.2 below).

\section{Data mining}

In addition to the borehole seal, data mining in the borehole and/or formation is a prerequisite for the instrumented drilling rods. If the inner volume of the "casing" (i.e. MeBo drill pipes in the ground) is the target, a simple plug with a data logger and transducers is sufficient to monitor, e.g. the equilibration of the hole and ambient values thereafter. If coupling to the formation is desired, a mechanism is needed that couples the transducers to the open-hole formation. For this purpose, we designed a small device at the base of the instrumented uppermost drill rod that has a small coil with PVC tubing (1 $\mathrm{mm}$ inner diameter) which can be unrolled via an electrical motor upon command (acoustic signal or timer with preset date/time for lowering). At the tip of the tubing there is a stainless steel conical drop weight with a boring that will then provide access to the sediment at the base of the hole. The tubing may then be used to get ambient pore pressure readings, or extract porewater samples (in case an osmosampler is hooked to it at the seafloor). We have realised designs of both in the MeBoPLUG and the MeBoCORK-A and MeBoCORK-B (see Sect. 3.2 below).

\section{Data transfer}

Retrieval of CORK data has always been a crucial issue in the past, with the majority of ODP-CORKs and IODP-CORKs relying on a remotely operated underwater vehicle (ROV) visits during regular third party cruises in the years after deployment. This is a costly endeavour and further bears the difficulty of vagueness in planning because of dependency on weather, ship time providers, etc. Only very few CORK systems were connected to seafloor cabled networks (e.g. ODP Hole 1026B to NEPTUNE, or ODP Site C0002 to DONET), so the requirement for ROV visits is reduced to instances of maintenance, not data transfer. In any case, one of the key requirements in developing MeBo observatories was hence to start with a simple instrument to be recovered by a ROV and then evolve into systems which make ROV visits or even visits of a vessel obsolete.

As a consequence, the MeBoCORK systems aimed at including acoustic modems so that the successful deployment and health of the system after the MeBo took off can be attested. Data transfer is moderately fast, so that practically only limited data sets are to be downloaded that way, while a final visit to recover the instruments by a ROV seems still advisable. In case the deployments take place in an area where a return cruise is not anticipated for longer periods of time, it may be better to release a pop-up unit with a mirror data set of the main data logger as well as an iridium telemetry to transfer the data without the necessity of retrieving the instrument. If the latter is sufficiently cheap, net cost may be saved since ship time is also precious. We have realised designs of both in the MeBoCORK-A and MeBoCORK-B and the MeBoPUPPI (Pop-Up Pore Pressure Instrument) (see Sect. 3.2 below).

\section{Increased payload}

Given the wealth of critical parameters that govern seafloor processes, scientist want to deploy multi-sensor instruments that often consume considerable energy. One main objective in MeBoCORK installation was hence to have a modular seafloor unit where space for additional devices and batteries play a minor role. Such a unit has to exchange the initial MeBoCORK instrument (with a limited lifetime) without affecting the borehole seal. This was achieved by a hotstab connector that can transport fluids, power, or both. At the seafloor end, capabilities may be increased by not only adding osmo-samplers with long tubing coils for fluid sampling over 24 months and longer but also providing power for energy-demanding systems, e.g. geophones. We have realised this by inventing the MeBoCORK-B (see Sect. 3.2 below).

In the next section we will introduce three general instruments of the MeBo observatory family: the PLUGs, CORKs, and PUPPIs. Each of them is employing several (if not all) of the tasks listed above. In addition to those observatory instruments realised, many other combinations of transducers and data transfer principles, but also implementation of new transducers. This could be either in the instrumented drill pipe (if sufficiently slim) or inside the seafloor unit. With its generic and modular design MeBo observatories may become a versatile and affordable way to monitor hydrogeochemical and geological processes in the shallow subseafloor $(<200 \mathrm{~m})$.

\subsection{Implementation}

\section{MeBoPLUG borehole observatories}

In regular-size industry boreholes, the casing of the upper portion on the well is a couple of decimetres, and re-entry into the hole is facilitated by a conical seafloor structure, often complemented by a platform to land a ROV. For the seafloor drill holes, all of this is miniaturised and in the case of MeBo a diameter of only $98-110 \mathrm{~mm}$ is available. Hence, space is most seriously governed the design of the MeBo observatories, and re-entry is not feasible in such narrow drill pipes. In essence, the entire hole completion was initially designed as a stand-alone instrument, which does not differ from the geometry of a standard MeBo drill pipe (approx. $235 \mathrm{~cm}$ long and $10 \mathrm{~cm}$ in diameter). 


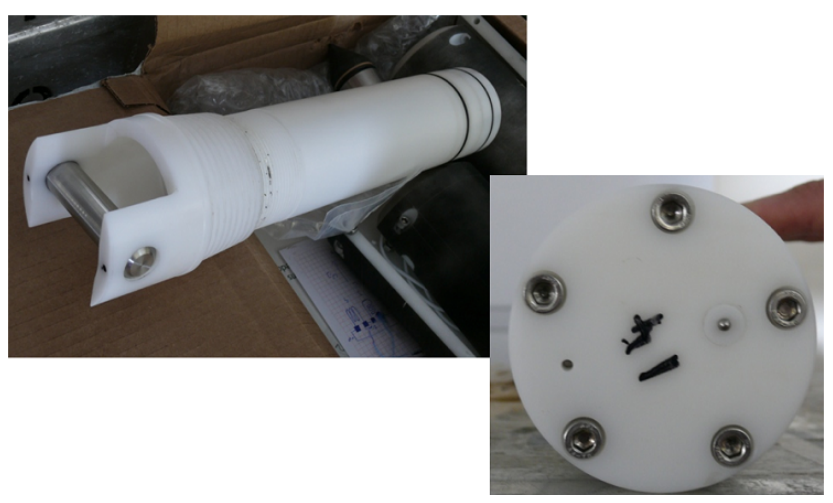

Figure 3. MeBoPLUG prior to being screwed into a MeBo drill pipe (left); photograph to the right shows bottom view into the borehole with ports for $\mathrm{P}$ (hole at left) and $\mathrm{T}$ (little pin at right) monitoring. See text.

The name of the instrument is extended from the SmartPlug and GeniusPlug observatories, which also represent simple types of CORKs designed as an extension to mechanical bridge plugs, but with IODP drill hole-sized (Kopf et al., 2001b). Instead of a bridge plug or CORK seal, we make use of the conical threads of the MeBo drill pipes and seal the pipe with a pair of additional o-rings (Fig. 3). The pressure housing is machined from a thermoplastic synthetic polymer, polyoxymethylene (POM), which tolerates moderate pressure and temperature and has successfully been used to $25 \mathrm{MPa}$ confining pressure. At the top, a handle designed to specification of the ROV MARUM-Quest manipulator was added. In the borehole-facing section, a thermistor as well as the downward-looking P port are situated (Fig. 3, inset on right).

Inside the housing we hosted standard "RBR Duo" data loggers (see www.rbr-global.com for detailed specifications) with Keller PD10 differential pressure transducers $(500 \mathrm{kPa}$ differential $P$ range) for monitoring pressure transients in the boreholes (as a proxy for strain; Davis et al., 2006) relative to the seafloor pressure signal. With this approach we omit de-tiding of our data because all signals, e.g. wave action, occur more or less simultaneously at the seafloor and in the shallow sub-seafloor formation. Given that only one thermistor was fitted into the so-called MeBoPLUGs, we are lacking a temperature record from the seafloor (i.e. upward-looking side of the MeBoPlug; see Fig. 3). In order to overcome this shortcoming, a simple self-contained device for sea bottom temperature monitoring, a so-called MTL (Miniature Temperature Logger by Antares; Pfender and Villinger, 2002) was deployed by a ROV next to the MeBoPLUG (see next section). The sampling rate of the MeBoPLUGs was set to $10 \mathrm{~s}$ on the RBR data loggers, which is providing them with an estimated lifespan of about 4 years (anticipated end of recording is February 2016).

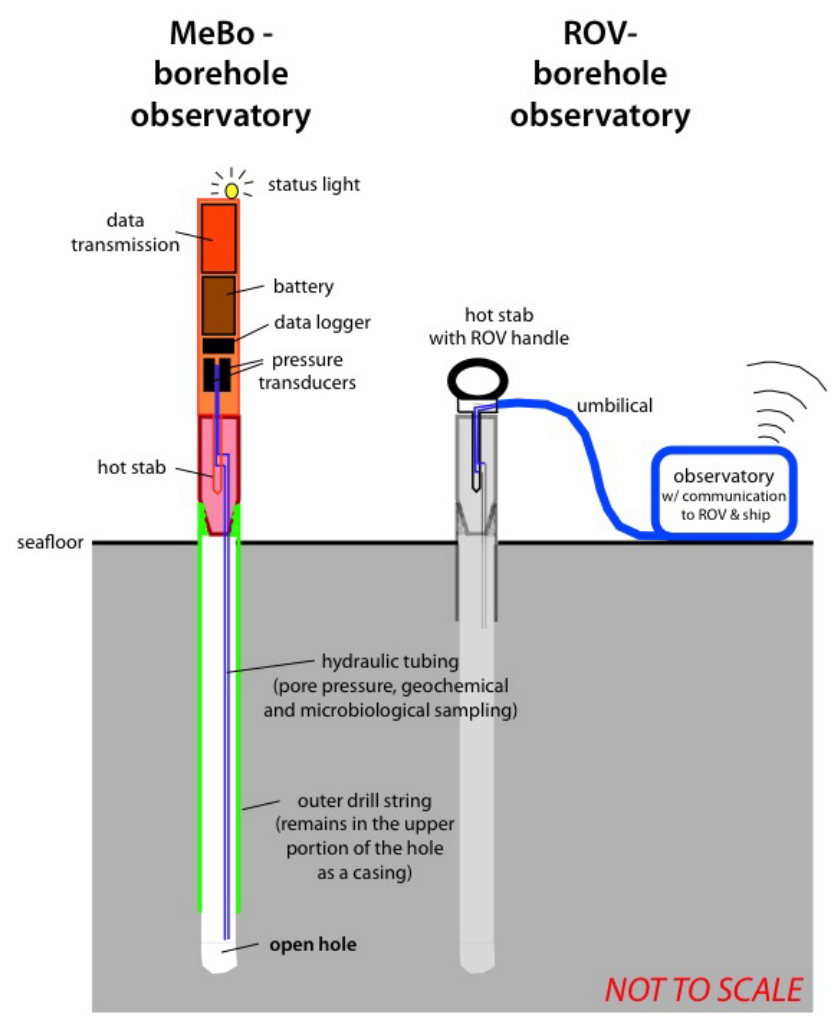

Figure 4. Schematic diagram of (a) MeBoCORK-A and (b) MeBoCORK-B.

\section{MeBoCORK borehole observatories}

The two versions of the MeBoCORK, as seen in Figs. 4, 5, 6 , and 7 , are both self-contained with power, data logging, data transmission, and transducers. They are recoverable at all times and hence minimise the risk of losing the investment. In the following paragraphs, the deployment mechanism is explained in some detail. First, the MeBo hole has to be prepared for long-term instrumentation after coring is completed. This is achieved by leaving several pieces of MeBo outer drilling rods in the ground after wireline core retrieval. These rods, approx. $30-40 \mathrm{~m}$ in total length, act as a casing and stabilise the upper sub-seafloor portion where the deposits are poorly consolidated and otherwise may close in. Only the lowermost part of the hole is free of "casing" and provides direct access to the formation. The first prerequisite to keep the MeBoCORK simple follows the first hydrological observatory in ODP: only hydraulic tubing is lowered into the hole to access fluid pressure (or fluids) at depth (Wheat et al., 2011), and all electronics remain at the wellhead. For MeBo, a string of two armoured PTFE (polytetrafluoroethylene) tubes is coiled up in the lower part of the MeBo set observatory unit (termed MeBoCORK-A, where A stands for "autonomous", i.e. MeBo by itself is capable of placing a stand-alone observatory), namely in the lower portion of the "adapter" hosting the receptacle for the hot stab. 

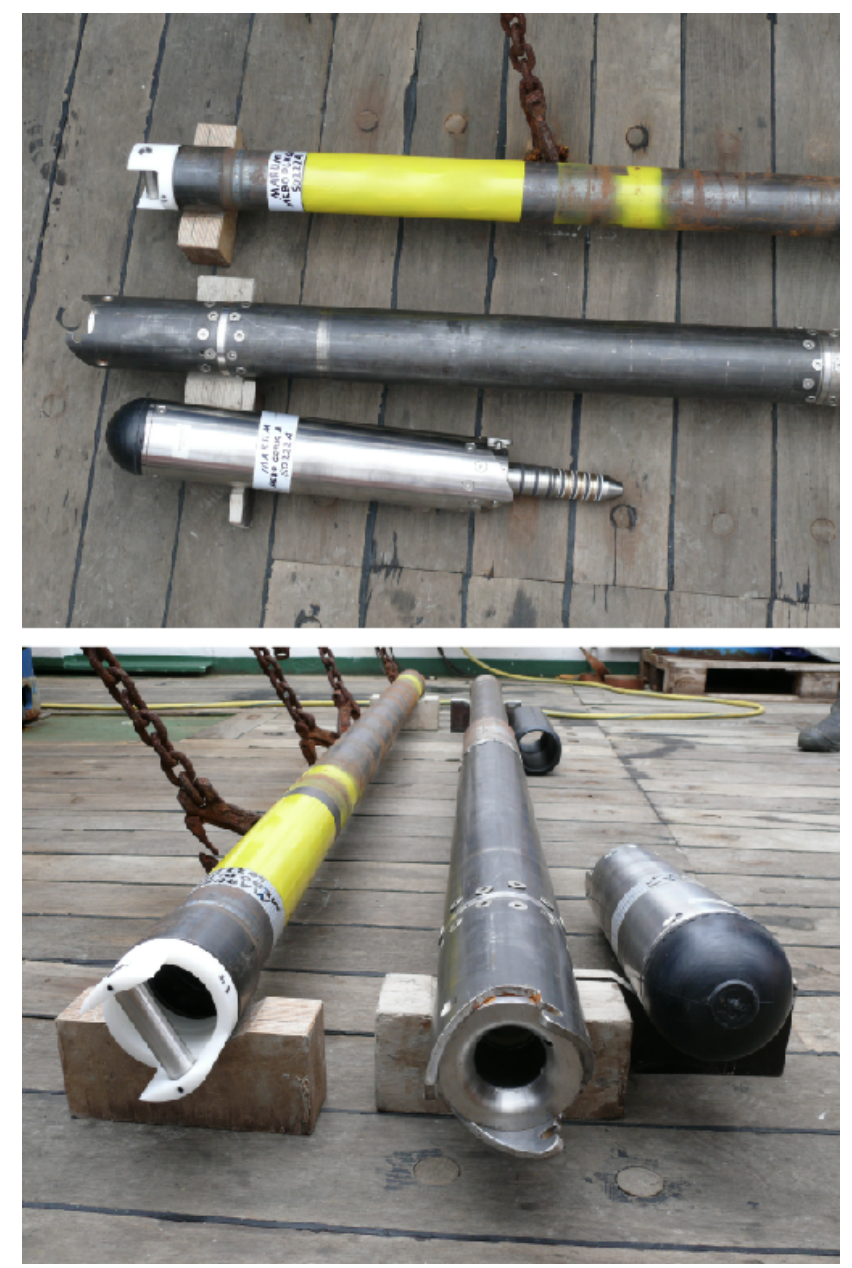

Figure 5. MeBoCORK A (i.e. autonomous) as well as MeBoPLUG for comparison. The MeBoPLUG is the white POM-made system screwed into the yellow rod, while the MeBoCORK-A is taken apart and has the actual monitoring and data unit with male hot-stab adapter taken out of its female counterpart. See text.

Once the drilling device has set this piece, the coil of tubing is unlocked and a dead weight favours the tubing's descent towards terminal depth where the hole is open. The upper end of the individual tubing connects to the borings of the hotstab receptacle. The lower unit also hosts battery packs. For the installations during cruise $\mathrm{SO} 222$, we pre-installed $45 \mathrm{~m}$ long tubes because we never aimed to exploit the full depth of MeBo in the mud volcanoes with fairly homogeneous mud breccia, although space would allow for up to $70 \mathrm{~m}$ of tubing.

The upper portion of the MeBoCORK-A hosts the data transmission unit, data logger, and transducers, the latter of which are connected to the borings of the male hot-stab end (Figs. 4a, 5). The hot stab is mated with its female counterpart, and the two halves of CORK-A are further secured by a bayonet connector that allows coupling of the MeBo70 top drive and hence torque being transmitted (in clockwise direction only). During installation MeBo fully screws in the entire CORK instrument, which in total is the exact length of a regular MeBo drill rod and which sits on the magazine with the other rods. Once this piece is properly set, MeBo pushes the unit to a depth so that only the titanium part (ca. $70 \mathrm{~cm}$ long) sticks out of the seafloor and then disconnects. In the initial design, this simple, MeBo set CORK monitors pressure and temperature, which are both indicators for deepseated fluid flow; pore pressure is additionally valuable as a strain proxy (see above). Depending on the sampling rate, the batteries will allow monitoring for many months to a few years (in case of the system deployed during leg SO222A, this was 7 months at a sampling rate of $1 \mathrm{~Hz}$; see below).

If monitoring as well as parameters other than pressure and temperature is desired, the instrumented MeBo70 rod (CORK-A) is too small and a ROV dive is required to recover the CORK-A and deploy an external, more sophisticated observatory unit (Figs. 4b, 6). Since the ROV dives to the seafloor and connects a seafloor (0 sea bottom) unit to the MeBo rod with a hot-stab receptacle, this system was termed MeBoCORK-B (i.e. bottom). The ROV is able to unlatch the bayonet connector in an anticlockwise direction and can transport the MeBo set CORK back to the ship, because its weight is low and the diameter is suitable for the manipulator claw. Before this, a seafloor unit will be placed next to the MeBo drill site (Fig. 6). This system consists of a pressure housing with an attached hood in which a male hotstab adapter plus the umbilical of armoured tubing strings is coiled up. The ROV takes the hot stab and places it into the lower portion of the MeBoCORK, which remains connected to the outer drill string at all times. Hot-stab operations are also common in IODP CORKs to enhance the capabilities for hydrogeological testing (e.g. Kopf et al., 2011a). The pressure housing at the seafloor can be equipped to the mission's/scientists' specifications, and in the case of this proposal will host the pressure and temperature transducers (same as in the instrumented rod) plus an osmo-sampler (Fig. 7; see also Jannasch et al., 2003).

Both MeBoCORK instruments are programmed to measure the pressure at $1 \mathrm{~Hz}$ for a period of $30 \mathrm{~s}$ and then record the average pressure value. Seafloor reference and borehole pressure are offset by $15 \mathrm{~s}$, so that the data are written to the disk alternately.

\section{MeBoPUPPI borehole observatories}

In a recent effort, we have taken the MeBo long-term borehole observatory science to the next level and built pop-up borehole instruments that can be released from the casing string after a predefined period. An underwater connector, which is Capable of being mated, further enables the user to also "manually" release the unit with a ROV. Once the unit has ascended to sea level, the pop-up units (Fig. 8) send their data via satellite link, rendering a second visit and additional ship time unnecessary. Such instruments would in a first iteration monitor pressure and temperature, but could be 

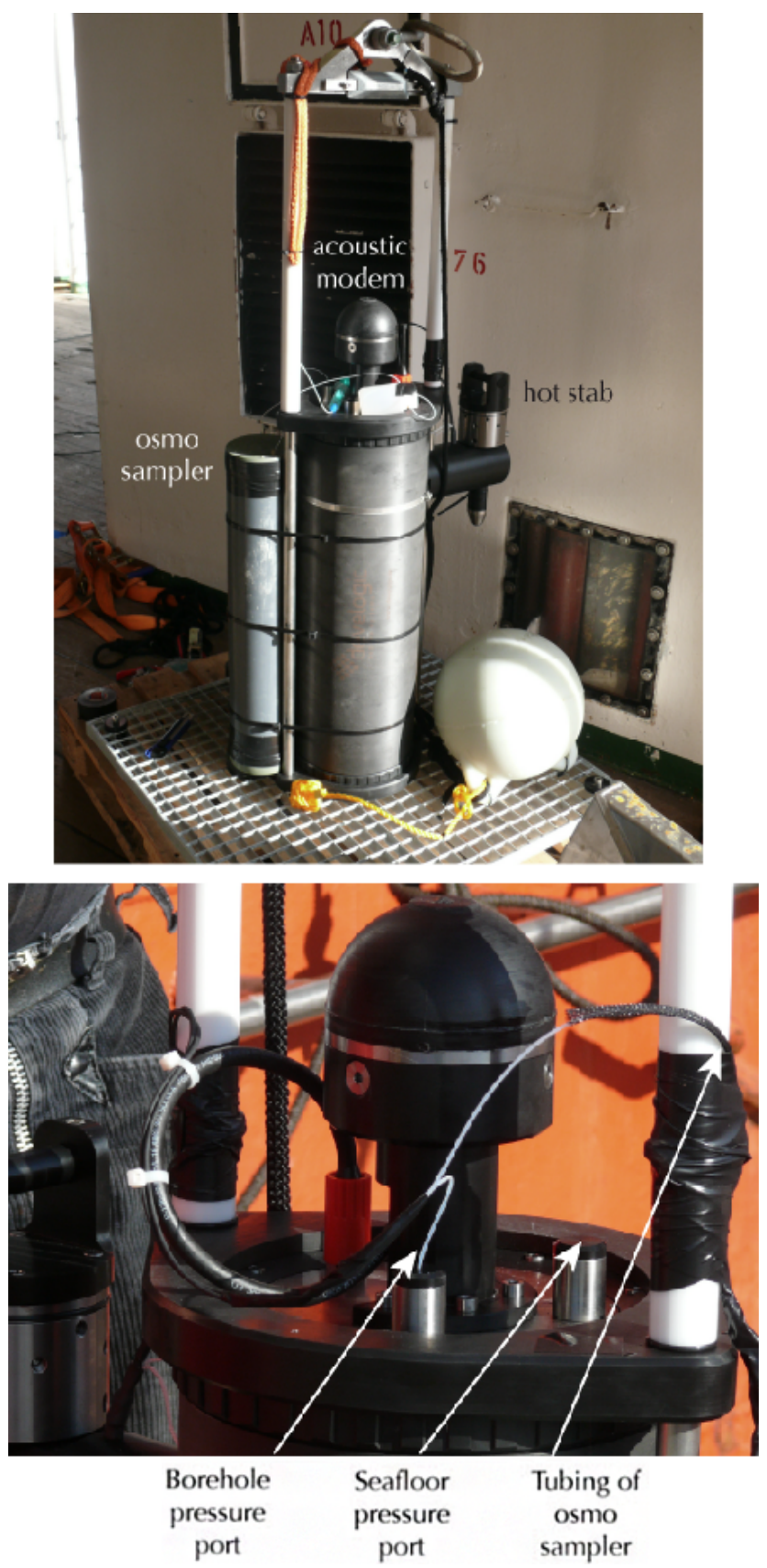

Figure 6. MeBoCORK B (i.e. bottom) unit containing a pressure housing, acoustic modem, attached osmo-sampler, and the hot-stab connector to couple to the drill pipe. Upper photo shows overall unit, lower photo contains detail with layout of tubing. See text.

equipped with geophones, seismometers, and other components depending on the scientific demands of a given mission, the duration of monitoring, the amount of time series data, etc.

In contrast to the MeBoCORK systems, the MeBoPUPPIs do not rely on a hot-stab connector and tubing that is lowered towards the terminal depth of the borehole where direct

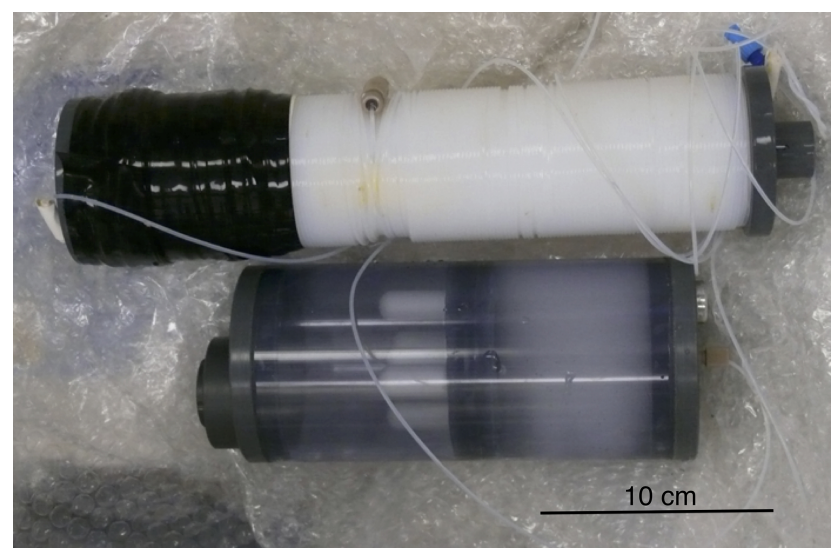

Figure 7. Osmo-sampler (tubing coil [top] and pumps [below]) that are hosted in a PVC tube attached to MeBoCORK-B.

access to the formation exists. Instead, the monitoring is restricted to pressure and temperature inside and outside of the borehole as well as tilt using a triaxial array of accelerometers. If desired, an additional unit that samples simultaneously one hydrophone and three geophone channels (type SM6, with $4.5 \mathrm{~Hz}$ lower frequency band, but no mechanical gimbaling system) can be mounted. Either sensing package has to remain in the borehole string for reasons of limited space and weight of the pop-up unit. This may be equally the case for part of the battery packs when very long monitoring periods are desired. In these cases, almost all of the total of $235 \mathrm{~cm}$ length of a MeBo70 drill rod segment, excluding a $53 \mathrm{~cm}$ long adapter to protect the glass dome (Fig. 8, righthand side drawing), are available.

\section{Results}

During cruise SO222 on RV Sonne, the MeBo70 was deployed 6 times in water depth between 1900 and $2050 \mathrm{~m}$. The main objective of this cruise was to install borehole observatories with the MeBo70; therefore, holes were only drilled down to $35 \mathrm{~m}$ b.s.f. or shallower. As explained before, the drilling procedure in observatory installations encompasses that only a few drill pipes are recovered to create open-hole conditions at the base, and that a drill pipe that already included either a MeBoPLUG or a MeBoCORK-A is added to terminate the hole near the seafloor. Once that final rod was set the MeBo70 took off vertically while being assisted by the winch, and was then recovered on deck.

As explained in more detail in Kopf et al. (2013), a total of four observatories were set with MeBo70 during cruise SO222 with RV Sonne, and in case of MeBoCORK-B assisted by a ROV. In general, operations went according to plan, in particular for MeBoPLUG no. 1 and MeBoCORKA. Both systems were pre-installed on the uppermost, final drill rod, which was pushed down into the seafloor so that only approx. $70-80 \mathrm{~cm}$ stuck out into the water column. Fig- 

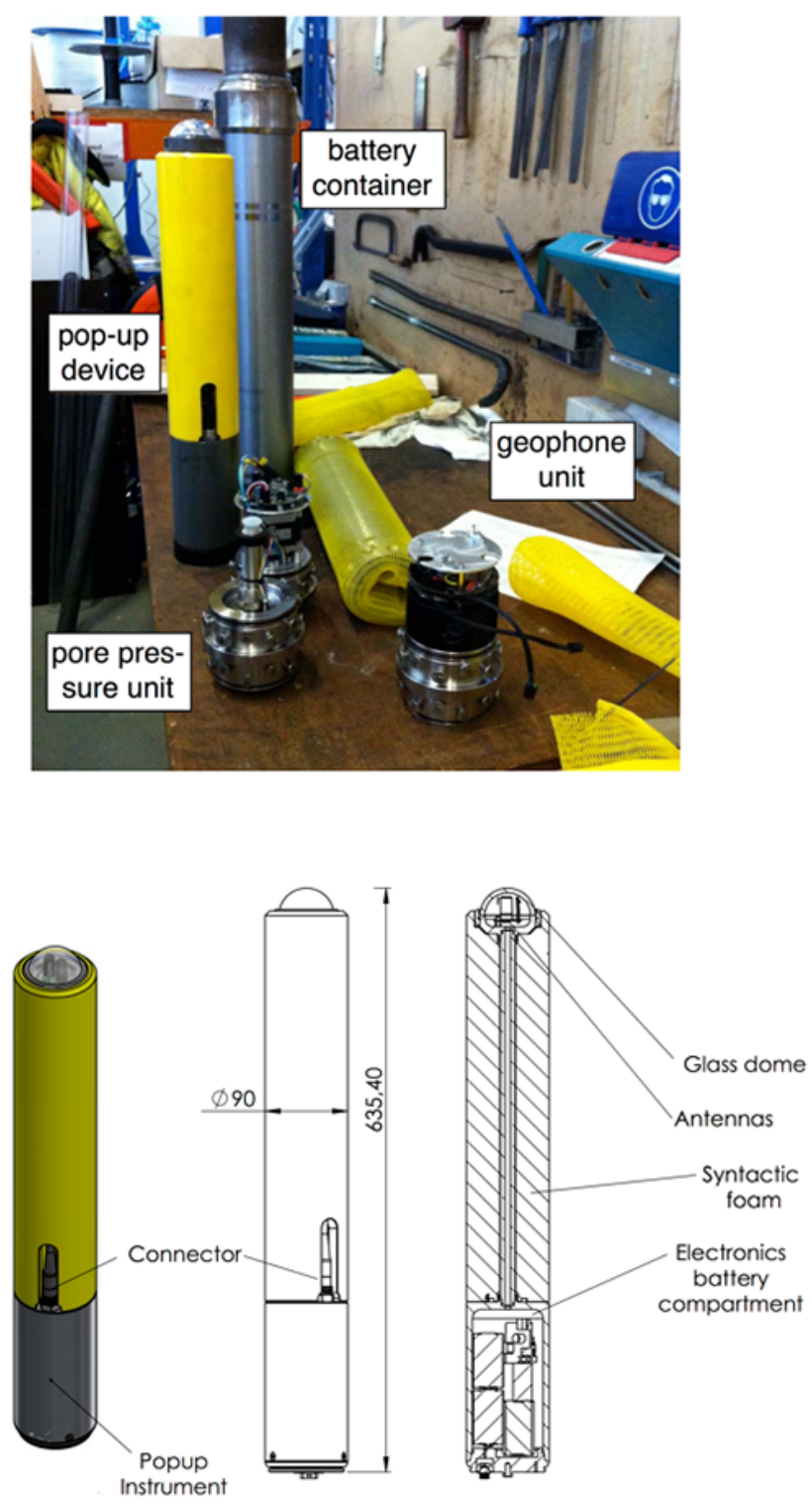

Figure 8. Schematic diagram (bottom) and photograph (top) of MeBoPUPPI observatory.

ure $9 \mathrm{a}$ and $\mathrm{b}$ illustrate how the situation looked like before MeBo70 took off.

When installing MeBoPLUG no. 2 in the Kumano Basin, we encountered some problems with drilling progress when hitting several indurated sand layers at approx. $17 \mathrm{mb}$.s.f. Despite efforts to clean the hole with pressurised fluid, the string did not progress any deeper, so that the only option to install MeBoPLUG no. 2 was to screw on the drill pipe section that hosted the MeBoPLUG and leave it sticking out of the seafloor by approx. $2.5 \mathrm{~m}$. Despite this fragile pipe representing an obstacle, the MeBo70 take-off went well and the pipe was not bent or damaged.

The majority of the other installations were also successful, e.g. for the autonomous CORK-A (Fig. 9c) and the

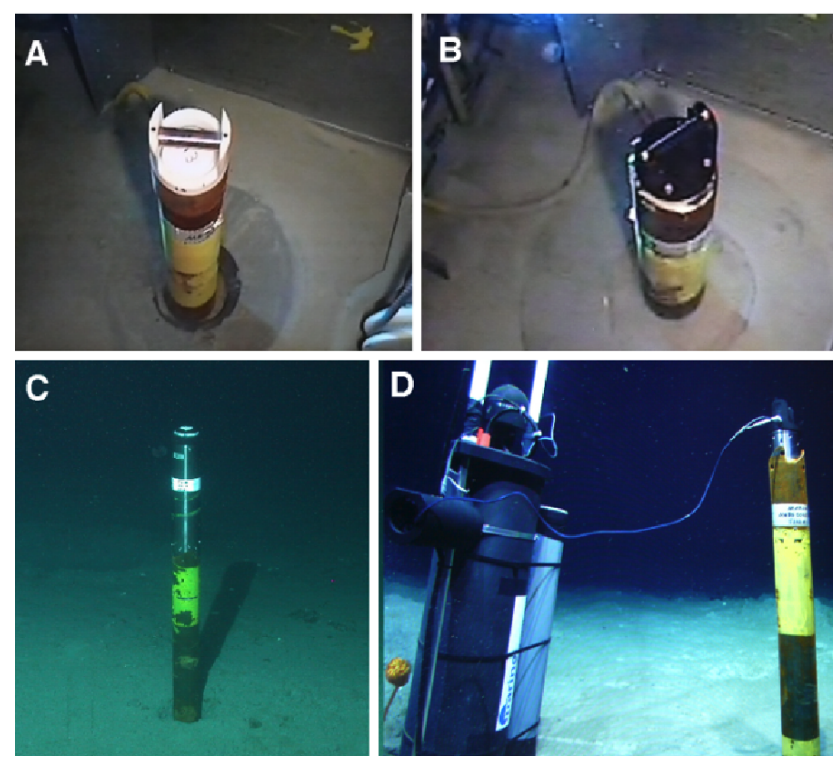

Figure 9. (a) MeBoPLUG and (b) MeBoCORK-B top hole assembly with black end cap after installation with MeBo70. Photos were taken immediately before the seafloor drill rig lifts off the ground. (c) MeBoCORK-A and (d) MeBoCORK-B with seafloor unit. Photos were taken during subsequent ROV visits. See text.

CORK-B downhole assembly with end cap protecting the female hot-stab end (Fig. 9b), as sighted later on by a ROV. In particular the latter example demonstrates that the black end cap on the female hot-stab connector (Fig. 9b) can be easily replaced with a hot stab on an umbilical that is connected to P transducers and osmo-samplers (Fig. 7), which are hosted in a pressure housing together with the data logger, acoustic data transmission, and other electronics (Fig. 9d).

During the installation of MeBoCORK-A at the crest of Kumano Basin mud volcano no. 4 (Kopf et al., 2013), we encountered no problems, and once the MeBo70 had taken off, we sent an acoustic signal to unlatch the drop weight and lower the coiled pore pressure tubing into the openbottom end of the otherwise cased drill hole. This process is controlled by an electrical motor which operates in either "command-mode" (triggered acoustically) or "timermode" (veering of tubing starts at a pre-programmed date and time). As can be seen from one of the first data sets downloaded from the CORK-A via acoustic communication system HAM.BASE by develogic $\mathrm{GmbH}$, the borehole pressure shows approx. $18 \mathrm{~m}$ higher pressure values than its seafloor counterpart (Fig. 10), which is in good agreement with the terminal depth of approx. $19 \mathrm{~m}$ b.s.f. at this drill site. It can further be observed that the borehole temperature is approx. $1.1^{\circ} \mathrm{C}$ warmer than the bottom water temperature (blue vs. turquoise data in Fig. 10).

At a neighbouring mud volcano, MV no. 3, we had at first no problem untangling the hot stab of the seafloor unit of MeBoCORK-B, taking it to the MeBo70 drill rod, and plug- 


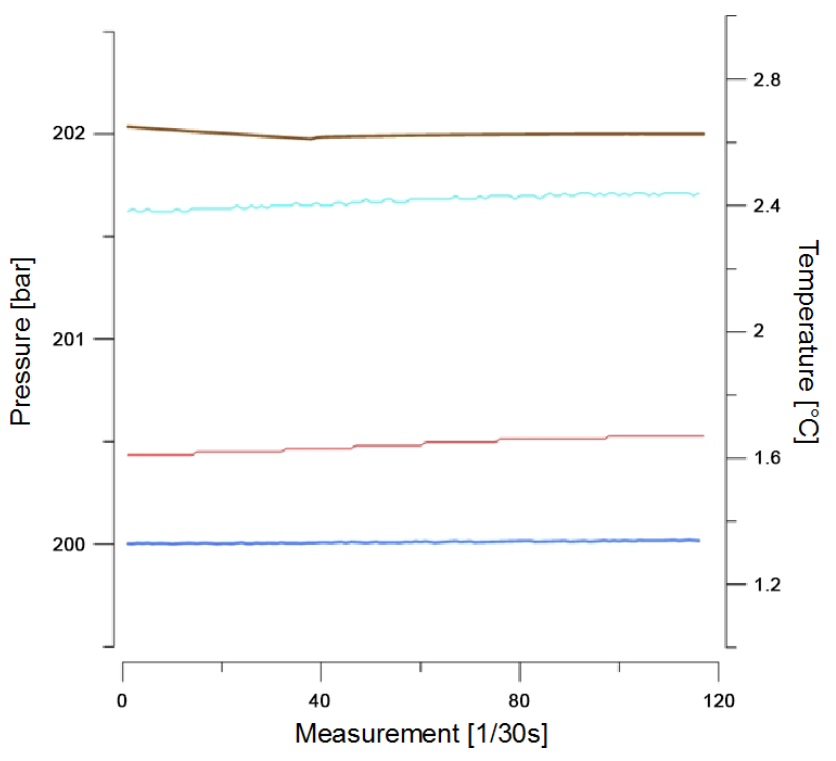

Figure 10. First data sets from MeBoCORK-A as recovered by acoustic data transmission. Pressure curves are blue/turquoise colours, $\mathrm{T}$ curves are red/brown colours (seafloor/borehole in either case). The $x$ axis represents the time over $60 \mathrm{~min}$, in which data are integrated over $30 \mathrm{~s}$ each. Note the offset in borehole vs. reference pressure, which attests the successful deployment of the drop weight and coiled tubing and access to the open-hole formation.

ging the hot stab into its female counterpart (Fig. 9d). However, there was some uncertainty that the tubing got caught and pinched during this operation, so that we unplugged the hot stab again and pushed it back in more safely a second time. The records of seafloor reference and downwardlooking (i.e. borehole) pressure are shown in Fig. 11. It can be seen that the differential pressures do not change much over the time of installation, which is unexpected given that the borehole terminates $33 \mathrm{~m}$ b.s.f. and the drop weight should sit near terminal depth of this hole. The only explanation for the $\mathrm{P}$ record measured is a leak somewhere inside the upper end of the female hot-stab end of the drill string; all other sources of error, including the entire bottom unit, umbilical with tubes to hot stab and osmo-sampler, as well as the hot-stab connector itself, are flawless.

Note that more details regarding the station work, but also regional geology and other in situ measurements in the Kumano Basin mud volcanoes can be found in the detailed cruise report by Kopf et al. (2013).

From a geological point of view, the few data sets we downloaded from the Kumano Basin mud volcanoes agree with other in situ measurements carried out during the same cruise. Both CPTu (cone penetration testing with pore pressure) and heat flow measurements indicate anomalies of pressure and temperature in the active features MV no. 3 and no. 4 (Kopf et al., 2013). Pore pressure in CPTu profiles reaches values of $30-70 \mathrm{kPa}$ in excess of hydrostatic, suggesting

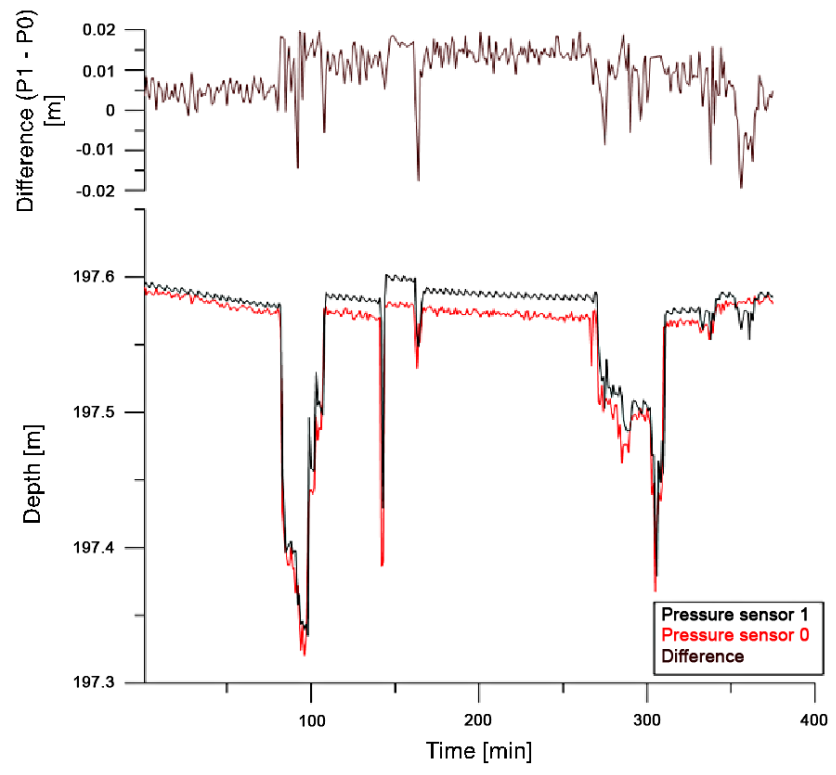

Figure 11. Data set covering the connection of MeBoCORK-B with the ROV Quest. For reasons to be explored, the borehole pressure is not any higher than the seafloor reference although the borehole is $33 \mathrm{~m}$ deep (i.e. the reading of the P sensor P1 in the lower plot's $y$ axis should have increased accordingly), suggesting a problem with the hot-stab connection. Note that the vertical scale is in metres $\times 10^{1}$ and that the horizontal unit is minutes.

hampered drainage and capture of deep-seated porewater in the ascending mud. This finding is supported by elevated heat flow, with geothermal gradients found to be around 0.064$0.122^{\circ} \mathrm{C} \mathrm{m}^{-1}$, whereas background levels ranged from 0.03 to $0.05^{\circ} \mathrm{C} \mathrm{m}^{-1}$. For details refer to Kopf et al. (2013).

\section{Discussion, conclusions, and outlook}

In summary, the "MeBoCORK concept" with its three versions (MeBoPLUG, MeBoCORK and MeBoPUPPI) aimed at a smart approach where an observatory can either be set by MeBo alone, or in combination with MeBo70 and a ROV. The designs represented a compromise scientifically since a limited set of parameters is monitored, however, this has not been any different when the first full-size ODP-CORKs were deployed (Becker and Davis, 2005). However, the three approaches taken appear extremely valuable at this stage and the future will likely provide opportunities for payload being added onto either observatory unit.

In the pilot study off the coast of Japan, we demonstrated that one MeBoCORK-A and one MeBoCORK-B as well as two MeBoPLUGs were successfully deployed. This meant that four out of a total of six MeBo holes drilled during a 2-week expedition got instrumented. For the MeBoPUPPIs, we are currently in the phase of long-term performance tests in the pool before taking them into the natural environment. 
Of course, the MARUM-MeBo borehole observatories are limited and high performance seismometers or strainmeters may turn out impossible to be installed because of both their size and energy consumption. However, it appears that future scientific ocean drilling may have to cope with such a mission-specific approach from ships of opportunity. In addition to it being most affordable, there are associated advantages such as the absence of heave on the system during installation (i.e. no danger of destroying the instruments). Future avenues to increase the payload of the MeBoPLUGs and MeBoCORKs are miniaturisation of transducers and optimisation of power consumption by the components, potentially combined with new ocean bottom fuel-cell technologies.

Acknowledgements. The authors thank the captain, Oliver Meyer, and crew of RV Sonne for the superb support when operating $\mathrm{MeBo}$ and the ROV during cruise SO222. The German Ministry for Education and Research (BMBF) is acknowledged for financially supporting the expedition (grant 03G0222 to A. Kopf). The MeBoCORKs and MeBoPUPPIs were funded via the German Science Foundation (DFG) through grants to A. Kopf (grant KO2108/16-1) and MARUM (via Excellence Initiative). The European Commission supported the work via FP7 projects MIDAS and ASTARTE. The design and development benefited from the expertise of Markus Motz and his team at develogic GmbH (Hamburg). The manuscript benefited from the detailed and thoughtful suggestions by Beth Orcutt and an anonymous referee.

The article processing charges for this open-access publication were covered by the University of Bremen.

Edited by: L. Eppelbaum

\section{References}

Becker, K. and Davis, E. E.: A review of CORK designs and operations during the Ocean Drilling Program, in: Proc. IODP, 301: College Station TX, edited by: Fisher, A. T., Urabe, T., Klaus, A., and the Expedition 310 Scientists, Integrated Ocean Drilling Program Management International, Inc., doi:10.2204/iodp.proc.301.104.2005, 2005.

Brown, K. M., Tryon, M. D., DeShon, H. R., Dorman, L. M., and Schwartz, S. Y.: Correlated transient fluid pulsing and seismic tremor in the Costa Rica subduction zone, Earth Planet. Sc. Lett., 238, 189-203, 2005.

Davis, E. E. and Becker, K.: Using ODP boreholes for studying subseafloor hydrogeology: Results from the first decade of CORK observations, Geosci. Can., 28, 171-178, 2001.

Davis, E. E. and Villinger, H.: Transient formation fluid pressures and temperatures in the Costa Rica forearc prism and subducting oceanic basement: CORK monitoring at ODP Sites 1253 and 1255, Earth Planet. Sci. Lett., 245, 232-244, 2006.

Davis, E. E., Becker, K., Wang, K., Obara, K., Ito, Y., and Kinoshita, M.: A discrete episode of seismic and aseismic deformation of the Nankai trough subduction zone accretionary prism and incoming Philippine Sea plate, Earth Planet. Sc. Lett., 242, 73-84, 2006.
Freudenthal, T. and Wefer, G.: Shallow drilling in the deep sea: The sea floor drill rig MeBo. Oceans '09 IEEE Bremen, IEEE Catalog Nr: CFP09OCF-CDR, ISBN:978-1-4244-2523-5, 2009.

Freudenthal, T. and Wefer, G.: Drilling cores on the sea floor with the remote-controlled sea floor drilling rig MeBo, Geosci. Instrum. Method. Data Syst., 2, 329-337, doi:10.5194/gi-2-3292013, 2013.

Jannasch, H. W., Davis, E. E., Kastner, M., Morris, J. D., Pettigrew, T. L., Plant, J. N., Solomon, E. A., Villinger, H. W., and Wheat, C. G.: CORK II: Long-Term monitoring of fluid chemistry, fluxes, and hydrology in instrumented boreholes at the Costa Rica subduction zone, in: ODP, Init. Repts, edited by: Morris, J. D., Villinger, H. W., Klaus, A. et al., 205, 1-36, 2003.

Johnson, H. P., Hutnak, M. Dziak, R. P., Fox, C. G., Urcuyo, I., Cowen, J. P., Nabelekk, J., and Fisher, C.: Earthquake-induced changes in a hydrothermal system on the Juan de Fuca mid-ocean ridge, Nature, 407, 174-177, 2000.

Kopf, A., Araki, E., Toczko, S., and Expedition 332 Scientists: Proc. IODP, Initial Reports 332: Washington, DC (Integrated Ocean Drilling Program Management International, Inc.), 190 pp., doi:10.2204/iodp.proc.332.2011, 2001a.

Kopf, A., Hammerschmidt, S., Saffer, D.M., Lauer, R., Davis, E. E., LaBonte, A., Meldrum, R., Heesemann, M., Macdonald, R., Toczko, S., Wheat, C. G., Jannasch, H., Edwards, K., Haddad, A., Orcutt, B., Villinger, H., Araki, E., Kitada, K., Kimura, T., and Kido, Y.: The SmartPlug and GeniusPlug: Simple retrievable observatory systems for NanTroSEIZE borehole monitoring, Proc. IODP, Vol. 332, 21pp., doi:10.2204/iodp.proc.332.105.2011, $2001 b$.

Kopf, A., Asshoff, K., Belke-Brea, M., Bergenthal, M., Bohrmann, G., Bräunig, A., Düssmann, R., Feseker, T., Fleischmann, T., Franke, P.D., Geprägs, P., Hammerschmidt, S., Heesemann, B., Herschelmann, O., Hüpers, A., Ikari, M. J., Kaszemaik, K. M., Kaul, N., Kimura, T., Kitada, K., Klar, S., Lange, M., Madison, M., Mai, A. H., Noorlander, C., Pape, T., Rehage, R., Reuter, C., Reuter, M., Rosiak, U. D., Schmidt, W., Seiter, C., Spiesecke, U., Stachowski, A., Steiner, A., Takanori, O., Tryon, M., Vahlenkamp, M., Wei, J., Wintersteller, P., and Zarrouk, M. K.: REPORT AND PRELIMINARY RESULTS of RV Sonne CRUISE SO222: MEMO - MeBo drilling and in situ Longterm Monitoring in the Nankai Trough accretionary complex, Japan. Berichte aus dem MARUM und dem Fachbereich Geowissenschaften der Univ. Bremen, 297, 123 pp., 2013.

McGinnis, T.: Seafloor Drilling, in: Drilling in extreme environments, edited by: Bar-Cohen, Y. and Zacny, K., Wiley, 309-345, 2009.

Orcutt, B., Wheat, C. G., and Edwards, K. J.: Subseafloor ocean crust microbial observatories: development of FLOCS (FLowthrough Osmo Colonization System) and evaluation of borehole construction materials, Geomicrobiol. J., 27, 143-157, 2010.

Pfender, M. and Villinger, H.: Miniaturized data loggers for deep sea sediment temperature gradient measurements, Mar. Geol., 186, 557-570, 2002.

Solomon, E., Kastner, M., Wheat, C. G., Jannasch, H. W., Robertson, G., Davis, E. E., and Morris, J. E.: Long-term hydrogeochemical records in the oceanic basement and forearc prism at the Costa Rica subduction zone, Earth Planet. Sc. Lett., 282, 240-251, 2009. 
Wang, K. and Davis, E. E.: Theory for the propagation of tidally induced pore pressure variations in layered subseafloor formations, J. Geophys. Res.-Solid Ea., 101, 11483-11495, 1996.
Wheat, C. G., Jannasch, H. W., Kastner, M., Hulme, S., Cowen, J., Edwards, K. J., Orcutt, B. N., and Glazer, B.: Fluid sampling from oceanoc borehole observatories: Design and methods for CORK activities (1990-2010), in: Proc. IODP, edited by: Fischer, A. T., Tsuji, T., Petronotis, K. et al., 327, doi:10.2204/iodp.proc.327.109.2011, 2011. 